\title{
S-allyl Cysteine, a Garlic Compound, Produces an Antidepressant-Like Effect and Exhibits Antioxidant Properties in Mice
}

\author{
Elizabeth Ruiz-Sánchez ${ }^{1}$, José Pedraza-Chaverri ${ }^{2}$ (D), Omar N. Medina-Campos ${ }^{2}$ (D), \\ Perla D. Maldonado ${ }^{3}$ and Patricia Rojas ${ }^{1, *(D)}$ \\ 1 Laboratory of Neurotoxicology, National Institute of Neurology and Neurosurgery \\ "Manuel Velasco Suárez", SS, Av. Insurgentes Sur No. 3877, Mexico City 14269, Mexico; \\ elizabeth.ruiz@innn.edu.mx \\ 2 Facultad de Química, Departamento de Biología, Universidad Nacional Autónoma de México, \\ CDMX 04510, Mexico; pedraza@unam.mx (J.P.-C.); omarnoelmedina@gmail.com (O.N.M.-C.) \\ 3 Laboratory of Cerebral Vascular Pathology, National Institute of Neurology and Neurosurgery \\ "Manuel Velasco Suárez", SS, Av. Insurgentes Sur No. 3877, Mexico City 14269, Mexico; \\ maldonado.perla@gmail.com \\ * Correspondence: prcastane@hotmail.com; Tel.: +52-55-5424-0808
}

Received: 30 July 2020; Accepted: 24 August 2020; Published: 26 August 2020

\begin{abstract}
Depression is a psychiatric disorder, and oxidative stress is a significant mechanism of damage in this mood disorder. It is characterized by an enhancement of oxidative stress markers and low concentrations of endogenous antioxidants, or antioxidants enzymes. This suggests that antioxidants could have an antidepressant effect. S-allyl cysteine (SAC) is a compound with antioxidant action or free radical scavenger capacity. The purpose of the current research was to evaluate the antidepressant-like effect as well as the antioxidant role of SAC on a preclinical test, using the Porsolt forced swim test (FST). SAC (30, 70, 120, or $250 \mathrm{mg} / \mathrm{kg}$, ip) was administered to male BALB/c mice daily for 17 days, followed by the FST at day 18. Oxidative stress markers (reactive oxygen species, superoxide production, lipid peroxidation, and antioxidant enzymes activities) were analyzed in the midbrain, prefrontal cortex, and hippocampus. SAC (120 mg/kg) attenuated the immobility scores (44\%) in the FST, and protection was unrelated to changes in locomotor activity. This antidepressant-like effect was related to decreased oxidative stress, as indicated by lipid peroxidation and manganese-superoxide dismutase (Mn-SOD) activity in the hippocampus. SAC exerts an antidepressant-like effect that correlated, in part, with preventing oxidative damage in hippocampus.
\end{abstract}

Keywords: S-allyl cysteine; Porsolt forced swim test; antidepressant-like effect; antioxidant defense; antioxidant enzymes; oxidative stress

\section{Introduction}

Depression is a prevalent and debilitating mental illness. It is related to a severe negative impact on the quality of life, and an increment in morbidity/mortality. It is identified by diverse symptoms related to impaired behavior, and affective, cognitive, and somatic functioning. It affects up to $20 \%$ of the population worldwide and can lead to early death, with social and economic consequences [1]. Although the molecular mechanisms underlying depression have not been elucidated, several lines of evidence indicate that oxidative stress, due to an overproduction of free radicals and/or decreased antioxidant capacity, plays a substantial part in this pathology $[2,3]$. 
Depressed patients have been described as having low concentrations of endogenous antioxidant compounds (coenzyme Q10, vitamin E, and zinc) and antioxidant enzymes, for example glutathione peroxidase (GPx), along with oxidative damage to deoxyribonucleic acid (DNA), alterations in mitochondrial function, and enhancement of lipid peroxidation (LPx) products [4,5]. These studies suggest that depression is associated with modifications in the balance between pro- and anti-oxidative processes.

In particular, the brain is susceptible when excessive reactive oxygen species (ROS) surpass the capacity of enzymatic and non-enzymatic antioxidants such as manganese superoxide dismutase (Mn-SOD), and copper-zinc SOD (Cu,Zn-SOD), catalase, GPx, glutathione reductase (GR), vitamin E, lipoic acid, and ferritin, among others. This results in oxidative stress, and in cell disturbance that leads to damage to lipids, proteins, and DNA, with subsequent structural and functional damage to cell membranes, inactivation of enzymes, and cell death [6].

Therefore, it is justifiable to suggest that several compounds with antioxidant action may be efficient in treating depression, since classical antidepressants have inconsistent efficacy, and many of them produce severe unwanted side effects. Indeed, it has been shown that antioxidants such as Ginkgo biloba extract (EGb 761), curcumin, and resveratrol can exert an antidepressant-like action accompanied by an antioxidant effect against oxidative stress [7-10].

Garlic (Allium sativum) is rich in sulfur-containing compounds, including S-allyl cysteine (SAC) and diallyl disulfide [11]. SAC is the active compound and the most abundant organosulfur molecule found in aged garlic extract and has multiple beneficial effects such as anti-cancer action [12], cholesterol-lowering action [13], and antioxidant and ROS scavenging effects [14]. SAC is known to scavenge ROS as superoxide anion $\left(\mathrm{O}_{2}{ }^{\bullet-}\right)$, hydrogen peroxide $\left(\mathrm{H}_{2} \mathrm{O}_{2}\right)$, hydroxyl radical $(\bullet \mathrm{OH})$, and peroxynitrite anion $\left(\mathrm{ONOO}^{-}\right)$[14]. It is a potent antioxidant agent, less toxic than other garlic antioxidants, water-soluble, stable, and easily absorbed by diverse tissues, including the brain [14].

SAC also has neuroprotective effects against ischemia-induced oxidative damage in rat brains [14], together with a decrease in oxidative stress markers in animal models of neurodegeneration such as Parkinson's [15] and Alzheimer's diseases [16]. The Porsolt forced swim test (FST) is the most common and established preclinical test for evaluating antidepressant-like responses under the stress induced by forcing the mice to swim [17], with good reliability and predictive validity [18]. Moreover, oxidative damage has been described in this model $[8,19,20]$. Thus, the present study aimed to investigate whether SAC exerts an antidepressant-like response associated with its antioxidant properties against FST-induced oxidative stress. We hypothesized that SAC administration will reduce depressive-like behavior, and this could be directly associated, in part, with its antioxidant action. Therefore, we analyzed immobility scores in the FST, spontaneous locomotor activity, LPx, ROS levels, $\mathrm{O}_{2}{ }^{\bullet-}$ production, and Mn-SOD, Cu, Zn-SOD, GPx, and GR activities.

\section{Materials and Methods}

\subsection{Drugs and Reagents}

SAC was synthetized as described previously [21], and was compared with a SAC standard based on melting point, ${ }^{1} \mathrm{H}$ nuclear magnetic resonance spectroscopy, and infrared spectroscopy [21]. GR, NADPH, xanthine, xanthine oxidase, nitroblue tetrazolium (NBT), bovine serum albumin (BSA), ethylenediaminetetraacetic acid (EDTA), reduced glutathione (GSH), glutathione disulfide (GSSG), $\mathrm{H}_{2} \mathrm{O}_{2}$, sodium diethyldithyocarbamate trihydrate (DDC), trichloroacetic acid (TCA), dihydroethidium (DHE), 1,1,3,3-tetramethoxypropane, and imipramine- $\mathrm{HCl}$ were from Sigma-Aldrich (St. Louis, MO, USA). Thiobarbituric acid (TBA), 2', $7^{\prime}$-dichlorofluorescein diacetate (DCFH-DA), and $2^{\prime}, 7^{\prime}$-dichlorofluorescein (DCF) were from Merck (Darmstadt, Germany). All other reagent-grade chemicals were commercially available. 


\subsection{Animals}

A total of 178 male BALB/c mice (Harlan, Mexico City, Mexico) at 11 to 13 weeks of age (25-30 g) were used in this experimental protocol. The animals were housed five per cage and maintained under a $12 \mathrm{~h}$ light-dark cycle (lights on at 7:00 a.m.), a relative humidity of $40 \%$ at $21 \pm 2{ }^{\circ} \mathrm{C}$, with water and food ad libitum up to the time of the experiment. The experimental protocol was carried out following the Mexican regulations for the Care and Use of Laboratory Animals (NOM-062-ZOO-1999), and it was approved by the Animal Care and Use Committee at the National Institute of Neurology and Neurosurgery. We made all efforts to minimize the number of animals used and their suffering. Experimental procedures were conducted between 9:00 and 15:00 $\mathrm{h}$ in the light phase of the circadian cycle by one experimenter. We allow a habituation time of $1 \mathrm{~h}$ before the experimental procedures.

\subsection{Experimental Design}

Experimental animals were divided in seven treatment groups: Group I: vehicle-treated + non-FST; Group II: vehicle-treated + FST; Group III: imipramine + FST; Group IV: SAC (30 mg/kg) + FST; Group V: SAC (70 mg/kg) + FST; Group VI: SAC (120 mg/kg) + FST; and Group VII: SAC (250 mg/kg) + FST. The control groups (I and II) were administered with saline solution. A classical antidepressant drug, imipramine, was used as a positive control. The experimental protocol of the current study is represented in Figure 1.

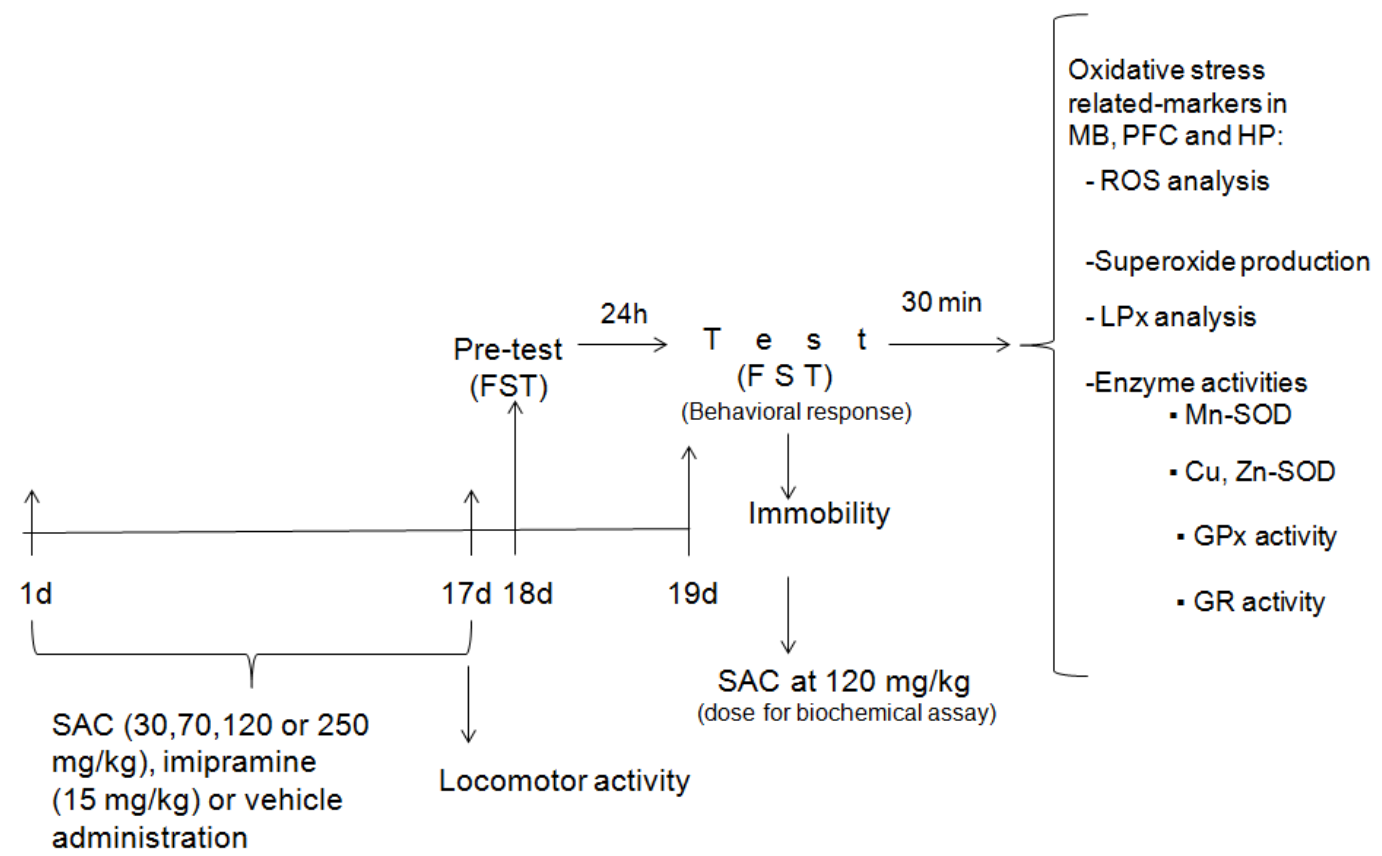

Figure 1. Schematic experimental protocol. FST = forced swimming test; $\mathrm{SAC}=\mathrm{S}$-allyl cysteine; $\mathrm{MB}=$ midbrain; $\mathrm{PFC}=$ prefrontal cortex; $\mathrm{HP}=$ hippocampus; $\mathrm{ROS}=$ reactive oxygen species; $\mathrm{LPx}=$ lipid peroxidation; $\mathrm{Mn}-\mathrm{SOD}=$ manganese-superoxide dismutase; $\mathrm{Cu}, \mathrm{Zn}-\mathrm{SOD}=$ copper, zinc-superoxide dismutase; GPx = glutathione peroxidase; GR = glutathione reductase.

The antidepressant-like effect of SAC was evaluated by administering different doses (30, 70, 120, or $250 \mathrm{mg} / \mathrm{kg}$, ip; $n=11-15$ animals per group), imipramine (15 mg/kg, ip; $n=13)$, or vehicle (ip; $n=10$ ) daily for 17 days. Animals were exposed to the FST at $24 \mathrm{~h}$ after the last drug administration. This procedure consisted of a pretest (day 18) and test (day 19), as described below. SAC at $120 \mathrm{mg} / \mathrm{kg}$ showed the best effect in the FST and these same mice receiving this dose, as well as of imipramine and control groups, used for testing behavioral responses, were analyzed for biochemical assays. Animals were added if necessary to complete the study. 
To analyze spontaneous locomotor activity, mice were included in three treatment groups without FST exposure: vehicle (ip; $n=11)$, imipramine ( $15 \mathrm{mg} / \mathrm{kg}$, ip; $n=13)$, and SAC $(120 \mathrm{mg} / \mathrm{kg}$, ip; $n=15)$.

Experimental procedures for oxidative stress assays (ROS levels, $\mathrm{O}_{2}{ }^{\bullet-}$ production, LPx, and antioxidant enzymes activities) were performed after the FST. Mice were allocated to four experimental groups as previously described. Then, thirty min after FST (day 19), mice were euthanized by decapitation to obtain the prefrontal cortex (PFC), midbrain (MB), and hippocampus (HP).

In particular, ROS levels and $\mathrm{O}_{2}{ }^{\bullet-}$ production were analyzed on the same animals. The samples from each brain region were assayed in 27 mice (ROS, $n=4-7$ animals per group; $\mathrm{O}_{2}{ }^{\bullet-}, n=4-5$ animals per group). LPx was performed on 37 mice ( $n=8-10$ animals per group).

The antioxidant enzymes' activities (Mn-SOD, Cu,Zn-SOD, GPx, and GR) were assayed on the same mice from animals used to test the antidepressant-like effects of SAC $(120 \mathrm{mg} / \mathrm{kg})$, imipramine and vehicle groups $(n=33)$. Animals used for this assay were for Mn-SOD ( $n=6-8$ mice per group), $\mathrm{Cu}, \mathrm{Zn}-\mathrm{SOD}$ ( $n=6-8$ mice per group), GPx ( $n=7-9$ mice per group), and GR ( $n=7-9$ mice per group). Aliquots of the tissue homogenate of each animal were measured, where samples were available for each of the measurements.

\subsection{FST}

Antidepressant-like responses were estimated in the FST, with minor modifications as described previously [22]. Mice were individually placed in a glass cylinder (12 cm in diameter, $30 \mathrm{~cm}$ high), and filled with tap water $\left(25 \pm 1^{\circ} \mathrm{C}\right)$ at the height of $15 \mathrm{~cm}$.

The test consisted of two exposures to the cylinder. On the first day (pre-test, $18 \mathrm{~d}$ ), the mice were placed individually for $15 \mathrm{~min}$ in the glass cylinder. After $24 \mathrm{~h}$ (test, $19 \mathrm{~d}$ ), the exposure was repeated but swim duration was reduced to a $6 \mathrm{~min}$ period. The total duration of passive floating (immobility behavior) was measured during this period. Immobility was established as floating passively in an upright position in the water, with only small movements made necessary to keep the head above the water surface.

\subsection{Spontaneous Locomotor Activity}

In order to investigate whether the immobility time in the FST is involved in the alterations of locomotor activity, we analyzed spontaneous locomotor activity using a method previously described [23]. Mice were administered with SAC (120 mg/kg, ip), imipramine (15 mg/kg, ip), or saline daily for 17 days, and $60 \mathrm{~min}$ after the last administration the experimental procedure was performed. Locomotor activity was measured on day 17 by using an activity meter Opto-Varimex minor (Columbus Instruments, Int., Columbus, OH, USA). The locomotion associated with ambulation was defined as the total distance traveled in $10 \mathrm{~min}$.

\subsection{ROS Determination}

ROS levels were measured in the homogenates of MB, PFC, and HP by a modified spectrophotometric method [24,25] based on the oxidation of DCFH-DA to DCF. The homogenates were combined with $50 \mathrm{mM}$ sodium phosphate buffer $\mathrm{pH} 7.4$ and $5 \mu \mathrm{M}$ DCFH-DA. DCF formation was followed for $30 \mathrm{~min}$ at $500 \mathrm{~nm}$ in a spectrophotometer (Beckman Coulter Inc., Brea, CA, USA). The results were indicated as the change in optical density (O.D.)/mg protein.

\section{7. $\mathrm{O}_{2}{ }^{\bullet-}$ Production Assay}

$\mathrm{O}_{2}{ }^{\bullet-}$ is an important $\mathrm{ROS}$ and was measured by a previously described method [24]. $\mathrm{O}_{2}{ }^{\bullet-}$ in brain tissue was evaluated through oxidation of DHE to ethidium (Eth). Homogenates were incubated with DHE $(0.2 \mathrm{mM})$, salmon testes DNA $(10 \mathrm{mg} / \mathrm{mL})$, and $50 \mathrm{mM}$ sodium phosphate buffer $\mathrm{pH}$ 7.4. Eth-DNA fluorescence was measured at $480 \mathrm{~nm}$ excitation and $610 \mathrm{~nm}$ emission in a Synergy HT multimode microplate reader (Biotek Instruments, Inc., Winooski, VT, USA). The results were expressed as fluorescence units/mg protein [25]. 


\subsection{LPx Analysis}

LPx, a widely oxidative stress marker that reflects lipid oxidation, was evaluated through thiobarbituric acid-reactive substances (TBA-RS) production, as reported previously by us [15]. This method mainly measures malondialdehyde (MDA) levels, a compound that results from the decomposition of polyunsaturated fatty acids. Brain regions were homogenized in $2 \mathrm{~mL}$ of a solution containing $50 \mathrm{mM}$ phosphate buffer (pH 7.0), $15 \mathrm{mM} \mathrm{NaCl}$, and $145 \mathrm{mM} \mathrm{KCl}$.

One milliliter of homogenate was stirred with $2 \mathrm{~mL}$ of the TBA reagent (containing $26 \mathrm{mM}$ TBA, $211 \mathrm{mM} \mathrm{HCl}$ and $6.6 \% \mathrm{TCA}$ ), and the mix was boiled for $30 \mathrm{~min}$, centrifuged at $2000 \times \mathrm{g}, 4{ }^{\circ} \mathrm{C}$ for $10 \mathrm{~min}$. The absorbance at $532 \mathrm{~nm}$ was read on an Epoch spectrophotometer (BioTek Instruments, Inc., Winooski, VT, USA). The results were expressed as nmoles of TBA-RS/mg protein. All samples were assayed in duplicate.

\subsection{Antioxidant Enzymes}

We analyzed the antioxidant system measuring the antioxidant enzymes activities, including Mn-SOD, Cu,Zn-SOD, GPx, and GR in brain homogenate tissue (PFC, MB, and HP).

\subsubsection{SOD Activity}

The assay is based on the inhibition of $\mathrm{O}_{2}{ }^{\bullet-}$-induced reduction of NBT to formazan by SOD as previously described [26]. For total SOD activity, $330 \mu \mathrm{L}$ of tissue homogenate was mixed with $2.45 \mathrm{~mL}$ of the reaction mixture $(122 \mu \mathrm{M}$ xanthine, $30.6 \mu \mathrm{M}$ NBT, $122 \mu \mathrm{M}$ EDTA, $49 \mathrm{mM}$ sodium carbonate, and $0.006 \% \mathrm{BSA}$ ). The reaction started with the addition of $50 \mu \mathrm{L}$ of xanthine oxidase $(2.8 \mathrm{U} / \mathrm{L})$. After $30 \mathrm{~min}$ at $27^{\circ} \mathrm{C}$, reactions were stopped by addition of $660 \mu \mathrm{L}$ of $0.8 \mathrm{mM} \mathrm{CuCl}_{2}$, and absorbance at $560 \mathrm{~nm}$ was read. By using $50 \mathrm{mM}$ DDC, Cu,Zn-SOD was inhibited, and then $\mathrm{Cu}, \mathrm{Zn}$-was calculated from the difference between total SOD and Mn-SOD activities. One unit is the amount of SOD in total that inhibits the rate of formazan formation by $50 \%$. Samples were measured in duplicate, and data were expressed as units/mg protein.

\subsubsection{GPx Activity}

The principle of this assay is that GPx catalyzes the reduction of $\mathrm{H}_{2} \mathrm{O}_{2}$, oxidizing GSH to form GSSG, which is recycled to its reduced form by GR and NADPH [8]. Tissue homogenate was added to the reaction mixture (50 mM potassium phosphate buffer ( $\mathrm{pH}$ 7.0), $1 \mathrm{mM}$ EDTA, $1 \mathrm{mM}$ sodium azide, $0.2 \mathrm{mM} \mathrm{NADPH}, 1 \mathrm{U} / \mathrm{mL}$ of GR, and $1 \mathrm{mM} \mathrm{GSH}$ ). It was then allowed to incubate for $5 \mathrm{~min}$ at room temperature before initiation of the reaction by the addition of $0.1 \mathrm{~mL}$ of $1.25 \mathrm{mM} \mathrm{H}_{2} \mathrm{O}_{2}$. Optical density was read at $340 \mathrm{~nm}$ on a Beckman DU-640 spectrophotometer (Beckman Coulter, Inc., Brea, CA, USA) every $60 \mathrm{~s}$ for $3 \mathrm{~min}$. The activity was determined from the slope of these lines ( $\mu$ moles of NADPH oxidized per min) using a molar extinction coefficient of NADPH $\left(6.22 \times 10^{-3} \mathrm{M}^{-1} \mathrm{~cm}^{-1}\right)$. Data are reported as units/mg protein.

\subsubsection{GR Activity}

The assay is based on the reduction of GSSG by NADPH in the presence of GR [8]. Fifty microliters of brain homogenate were added to $950 \mu \mathrm{L}$ of reaction mixture $(0.10 \mathrm{M}$ sodium phosphate buffer (pH 7.6), $1 \mathrm{mM} \mathrm{GSSG}, 0.1 \mathrm{mM}$ NADPH, and $0.5 \mathrm{mM}$ EDTA), and the absorbance was measured at $340 \mathrm{~nm}$, every $60 \mathrm{~s}$ for $3 \mathrm{~min}$. The activity was calculated from the slope of these lines ( $\mu$ moles of NADPH oxidized per min) using a molar extinction coefficient of NADPH $\left(6.22 \times 10^{-3} \mathrm{M}^{-1} \mathrm{~cm}^{-1}\right)$. Data are reported as units/mg protein. 


\subsection{Statistical Analysis}

One-way analyses of variance (ANOVA) and post hoc Duncan's tests (SPSS Statistics 20 software; SPSS Inc., Chicago, IL, USA) were used to compare data. Values of $p<0.05$ were considered to be statistically significant.

\section{Results}

\subsection{SAC Exhibits an Antidepressant-Like Effect in the FST}

The one-way ANOVA showed a statistically significant response for SAC and imipramine (classical antidepressant) on immobility scores $(\mathrm{F}(5,69)=17.614, p=0.000)$. Both significantly reduced the duration of immobility in the FST (Figure 2A), suggesting that SAC produces an antidepressant-like response. This effect was statistically significant with reduction of $30 \%, 31 \%, 44 \%$, and $29 \%$ for 30 , 70,120 , and $250 \mathrm{mg} / \mathrm{kg}$ of SAC, respectively, when compared to the vehicle-treated control group (Duncan post-hoc $p<0.001$ ). SAC at $120 \mathrm{mg} / \mathrm{kg}$ was used to analyze ROS levels, $\mathrm{O}_{2}{ }^{\bullet-}$ production, $\mathrm{LPx}$, spontaneous locomotor activity, and the activity of different antioxidant enzymes because it was the most effective dose.

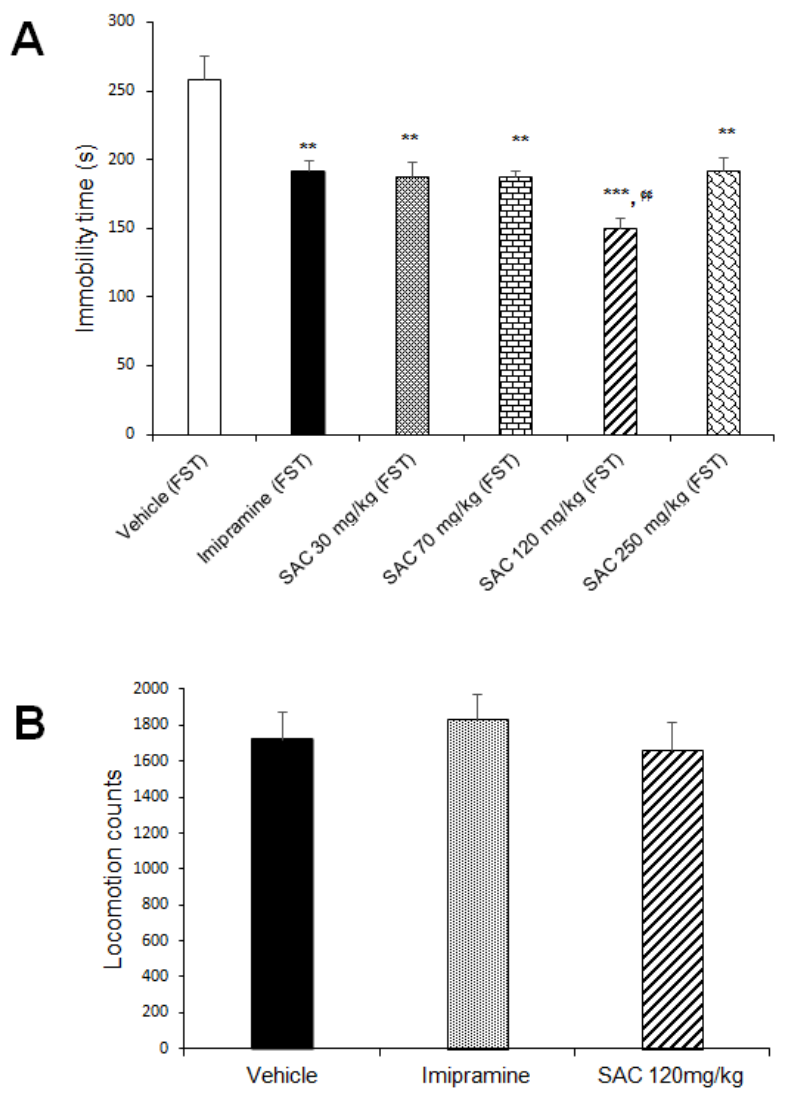

Figure 2. SAC produced an antidepressant-like response in the FST (A) and did not alter locomotor activity (B). Before FST, vehicle, imipramine $(15 \mathrm{mg} / \mathrm{kg})$, or SAC $(30,70,120$, or $250 \mathrm{mg} / \mathrm{kg})$ were administered to mice daily for 17 days. Immobility time (in seconds) and locomotion scores are expressed as mean \pm SEM, with 9-15 mice per group for antidepressant-like response and 11-15 mice per group for locomotor activity. The one-way ANOVA followed by post hoc Duncan's test was used to analyze differences among groups. (**) Statistically different from the vehicle-FST group (control group, $p<0.01$, Duncan's test; $(* *)$ Statistically different from the vehicle-FST group (control group), $p<0.001$, Duncan's test; ( $₫$ ) statistically different from imipramine (FST) group, $p<0.01$, Duncan's test. FST $=$ forced swimming test; SAC = S-allyl cysteine. 


\subsection{Antidepressant-Like Response to SAC is Not Related to Altered Spontaneous Locomotor Activity}

Data obtained in the spontaneous locomotor activity test were analyzed in the different groups (Figure 2B). SAC $(120 \mathrm{mg} / \mathrm{kg})$ and imipramine did not alter locomotor activity as compared to the vehicle-treated control group $(\mathrm{F}(2,36)=0.404, p=0.671)$. This suggests that SAC exerts a selective antidepressant-like response since spontaneous locomotor activity was not affected.

\subsection{Effect of SAC on ROS Levels in Mice Exposed to FST}

The amount of ROS in different brain regions is shown in Figure 3. The one-way ANOVA exhibited statistically significant differences among the groups $(\mathrm{MB}: \mathrm{F}(3,23)=3.75, p=0.026$, Figure 3A; PFC: $\mathrm{F}(3,15)=3.214, p=0.05$, Figure 3B; HP: F $(3,20)=3.71 ; p=0.029$, Figure 3C). Post hoc multiple comparison tests (Duncan post hoc $p<0.05$ ) showed that the vehicle-FST group reduced ROS levels in $\mathrm{MB}$ as compared to the non-swimming group (36\%). However, ROS levels were increased in the same brain region in the imipramine-FST group vs. the FST-group (46\%), SAC $(120 \mathrm{mg} / \mathrm{kg})$ administered to FST group showed a statistically significant reduction in ROS levels in MB compared to the imipramine-FST group (25\%) and non-FST group (31\%).

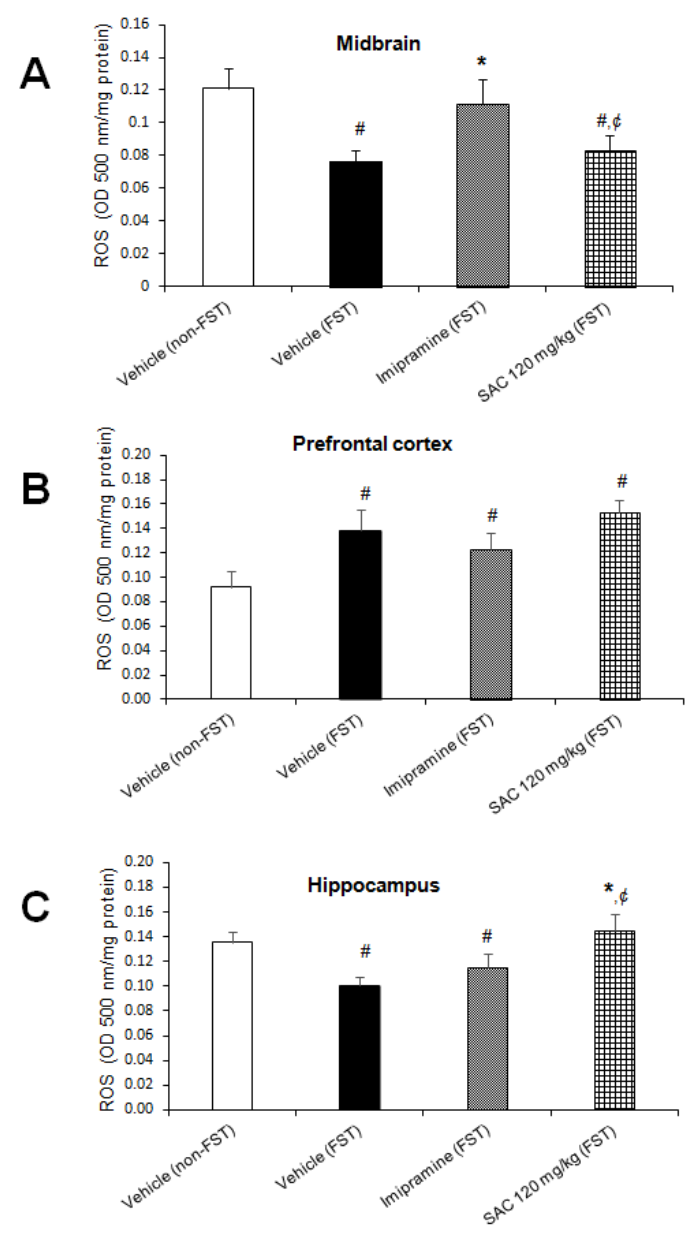

Figure 3. Effect of SAC on ROS levels in several brain regions of animals subjected to FST. The vehicle (non-FST), vehicle (FST), imipramine (FST) or SAC $(120 \mathrm{mg} / \mathrm{kg})$ were the treatment groups. SAC did not reduce the ROS amount in the midbrain (A), prefrontal cortex (B), or hippocampus (C) in the FST vs. vehicle-FST group. Results are expressed as mean \pm SEM of 4-7 animals per group. The one-way ANOVA followed by post hoc Duncan's test was used to analyze differences among the groups. (\#) statistically different from vehicle non-FST group, $p<0.05$, Duncan's test; $\left.{ }^{*}\right)$ statistically different from vehicle-FST group, $p<0.05$; ( $)$ statistically different from imipramine (FST) group, $p<0.05$, Duncan's test. FST = forced swimming test; $\mathrm{SAC}=\mathrm{S}$-allyl cysteine; $\mathrm{ROS}=$ reactive oxygen species. 
We have shown that FST was able to increase the ROS levels in PFC as compared to the non-FST group (50\%, Figure 3B). SAC (120 mg/kg) and imipramine administration in animals exposed to FST did not change the enhancement of ROS. In particular, FST group produced a significant reduction in ROS formation in HP (25\%, Figure 3C), but the SAC-FST group increased ROS formation as compared to the vehicle-FST group (44\%, Figure 3C) and to the imipramine-FST group (26\%, Figure 3 C).

\subsection{Effect of SAC on $\mathrm{O}_{2}{ }^{\bullet-}$ Production in Mice Exposed to FST}

$\mathrm{O}_{2}{ }^{--}$is an important $\mathrm{ROS}$ that can cause oxidative damage. No changes were found in $\operatorname{MB}(\mathrm{F}(3,13)=2.198, p=0.137$; Figure 4A), $\operatorname{PFC}(\mathrm{F}(3,16)=0.699, p=0.566$; Figure 4B), and $\operatorname{HP}(\mathrm{F}(3,13)=1.645, p=0.027$; Figure $4 \mathrm{C})$ in the different treatment groups. However, SAC $(120 \mathrm{mg} / \mathrm{kg})$ treatment showed a trend to reduce $\mathrm{O}_{2}{ }^{\bullet-}$ production in MB and HP.

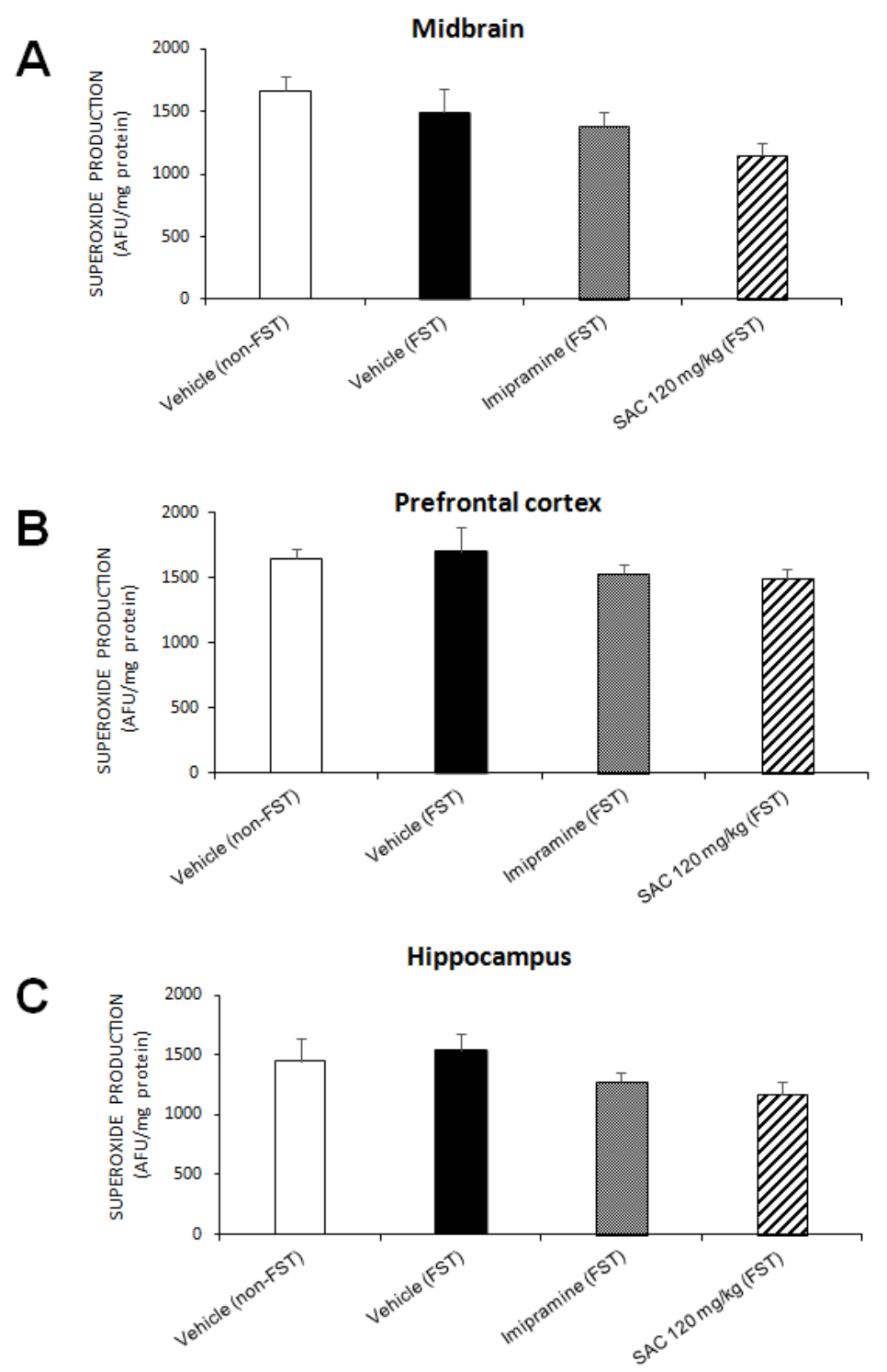

Figure 4. Effect of SAC on $\mathrm{O}_{2}{ }^{\bullet-}$ production in several brain regions in mice subjected to FST. The vehicle (non-FST), vehicle (FST), imipramine (FST) or SAC $(120 \mathrm{mg} / \mathrm{kg})$ were the treatment groups. SAC did not reduce $\mathrm{O}_{2}{ }^{--}$production in the midbrain (A), prefrontal cortex (B), or hippocampus (C) in the FST vs. vehicle-FST group. Results are expressed as mean \pm SEM of $4-5$ animals per group. The one-way ANOVA was used to analyze results. FST = forced swimming test; SAC = S-allyl cysteine; AFU $=$ arbitrary fluorescence units; $\mathrm{O}_{2}{ }^{\bullet-}=$ superoxide radical. 
3.5. Antidepressant-Like Behavior exerted by SAC Is Related with the Decrease in LPx in HP in Mice Exposed to FST

To analyze whether the antidepressant-like effect of SAC $(120 \mathrm{mg} / \mathrm{kg})$ was associated in preventing damage caused by oxidative stress, the TBA-RS assay provided an index of LPx (Figure 5).

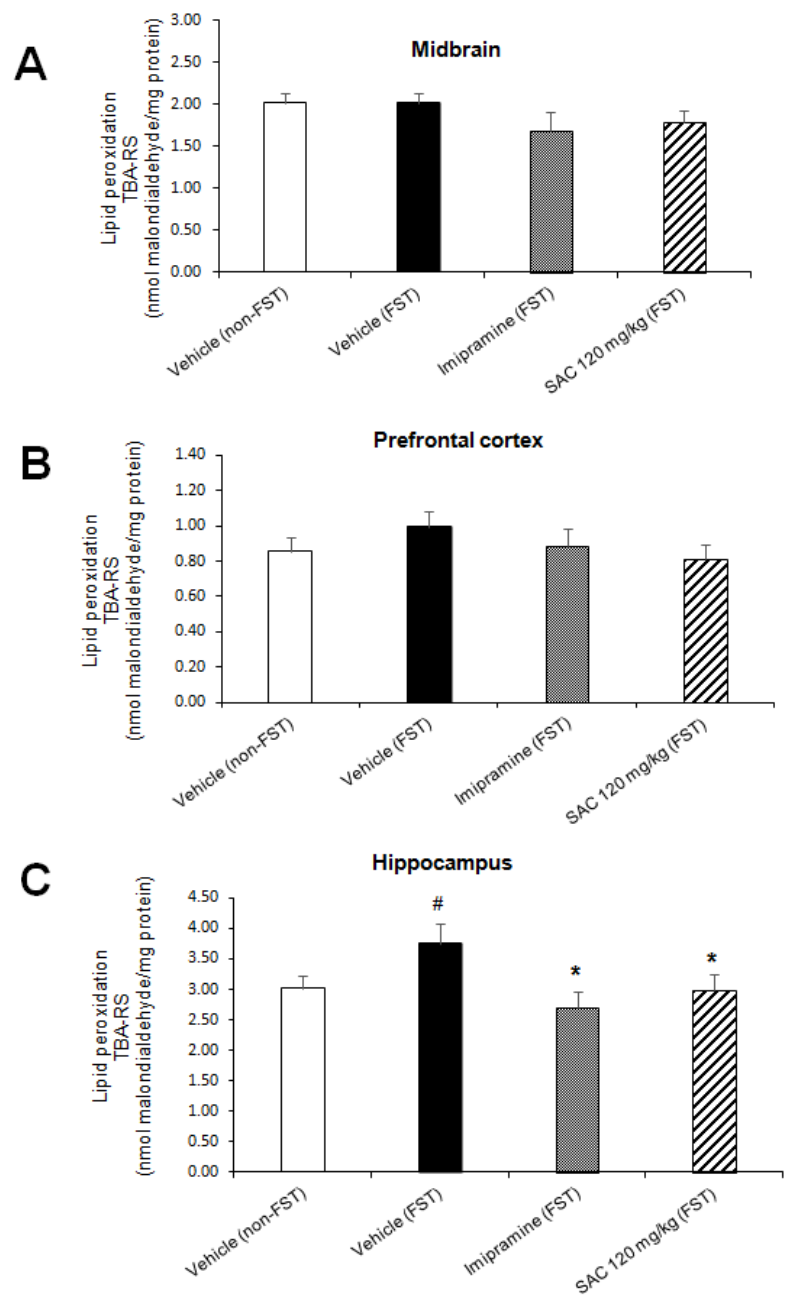

Figure 5. The antidepressant-like behavior of SAC is associated with a reduction in lipid peroxidation in the hippocampus of animals subjected to FST. The vehicle (non-FST or FST), imipramine (FST) or SAC $(120 \mathrm{mg} / \mathrm{kg}$ ) were the treatment groups. The thiobarbituric acid-reactive substances (TBA-RS) assay was used to measure lipid peroxidation in the midbrain (A), prefrontal cortex (B), and hippocampus (C). Results are expressed as mean \pm SEM of 8-10 animals per group. The one-way ANOVA followed by post hoc Duncan's tests was used to analyze the differences among groups. (\#) Statistically different from vehicle non-FST group, $p<0.05$, Duncan's test; $\left({ }^{*}\right)$ statistically different from vehicle (FST) group, $p<0.05$, Duncan's test. FST $=$ forced swimming test; SAC $=$ S-allyl cysteine.

There was a statistically significant difference in LPx in $\mathrm{HP}$ among the groups $(\mathrm{F}(3,31)=2.919$, $p=0.05$; Figure 5C). Post hoc multiple comparisons (Duncan post-hoc $p<0.05$ ) showed a significant increase in LPx after FST as compared to the non-FST group (24\%). Imipramine administration reduced LPx after FST vs. the vehicle-FST group (28\%). We demonstrated that SAC $(120 \mathrm{mg} / \mathrm{kg})$ administered to mice exposed to FST produces a significant reduction in LPx of HP vs. the vehicle-FST group $(20 \%$, Figure $5 \mathrm{C})$. No changes were found in $\operatorname{MB}(F(3,31)=1, p=0.406$; Figure $5 \mathrm{~A})$ and $\operatorname{PFC}(\mathrm{F}(3,29)$ $=0.805 ; p=0.501 ;$ Figure $5 \mathrm{~B}$ ) in different treatment groups. 


\subsection{Effect of SAC on Antioxidant Enzymes Activities in Mice Subjected to FST}

To investigate whether SAC $(120 \mathrm{mg} / \mathrm{kg})$ produces a protective effect via enzymatic antioxidant mechanisms in mice exposed to FST, we analyzed Mn-SOD, Cu,Zn-SOD, GPx, and GR activities.

The one-way ANOVA showed significant differences in Mn-SOD activity among groups in MB $(\mathrm{F}(3,23)=9.696, p=0.000$, Figure $6 \mathrm{~A})$, and $\operatorname{HP}(\mathrm{F}(3,25)=4.662 ; p=0.010$; Figure 6C). Post hoc multiple comparisons (Duncan post-hoc $p<0.05$ ) showed that FST enhanced Mn-SOD activity in MB as compared to the non-swimming group (36\%, Figure 6A). However, FST did not change Mn-SOD activity in the HP vs. the non-FST group.

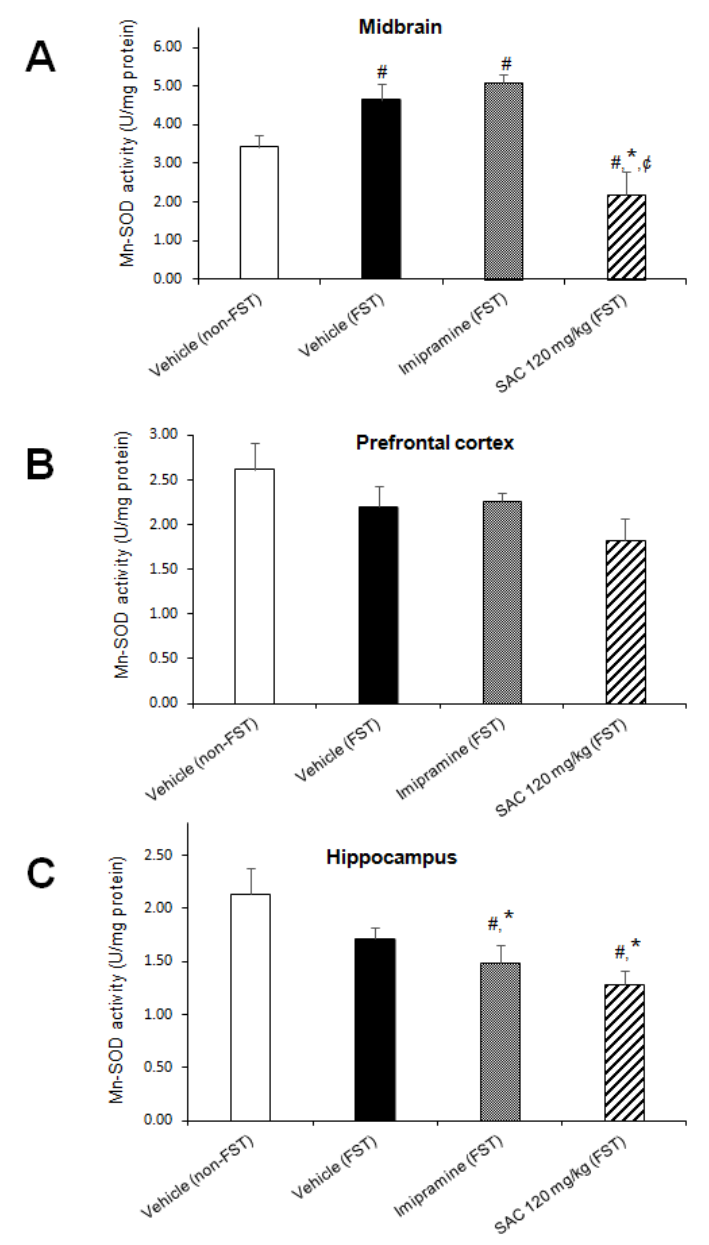

Figure 6. The antidepressant-like behavior exhibited by SAC $(120 \mathrm{mg} / \mathrm{kg})$ in the FST is related with downregulation of Mn-SOD activity in midbrain and hippocampus. The vehicle (non-FST or FST), imipramine (FST) or SAC $(120 \mathrm{mg} / \mathrm{kg})$ were the treatment groups. Mn-SOD was analyzed in the midbrain (A), prefrontal cortex (B), and hippocampus (C). Results are expressed as mean \pm SEM of 6-8 animals per group. The one-way ANOVA followed by post hoc Duncan's tests was used to analyze the differences among groups. (\#) Statistically different from the non-FST group, $p<0.05$, Duncan's test; ${ }^{*}$ ) statistically different from the vehicle-FST group, $p<0.05$, Duncan's test; ( $\mathbb{(}$ ) statistically different from the imipramine-FST group, $p<0.05$, Duncan' test. Mn-SOD = manganese-superoxide dismutase; $\mathrm{FST}=$ forced swimming test; SAC $=$ S-allyl cysteine.

On the other hand, FST did not alter Mn-SOD activity in the imipramine group in MB when compared to the control group (vehicle-FST). However, a reduction in Mn-SOD activity in HP was shown by the imipramine group exposed to FST (13\%, Figure 6C) vs. the FST group. SAC $(120 \mathrm{mg} / \mathrm{kg})$ reduced Mn-SOD activity in MB (53\%; Figure 6A), and HP (25\%, Figure 6C) after FST compared to the vehicle-FST group. It is suggested that an early mechanism induced by SAC is acting as an $\mathrm{O}_{2}{ }^{\bullet-}$ 
scavenger that prevents enhancement of Mn-SOD activity. SAC (120 mg/kg) reduced Mn-SOD activity in MB after FST compared to the imipramine-FST group (62\%, Figure $6 \mathrm{~A})$.

No changes were found in PFC in the different treatment groups $(\mathrm{F}(3,26)=2.076 ; p=0.128$; Figure 6B).

There was a statistically significant difference in $\mathrm{Cu}, \mathrm{Zn}-\mathrm{SOD}$ activity among the groups in $\mathrm{MB}$ $(\mathrm{F}(3,22)=4.010, p=0.02$; Figure 7A $)$ and PFC $(\mathrm{F}(3,25)=9.784, p=0.000$; Figure 7B $)$, but not in HP. Post hoc multiple comparisons (Duncan post hoc $p<0.05$ ) showed a significant reduction in MB (15\%, Figure 7A) after FST when compared to the non-swimming group (non-FST). Imipramine administration reduced Cu,Zn-SOD activity in MB (13\%, Figure 7A) as well as in PFC (34\%, Figure 7B) after FST (imipramine-FST vs. vehicle-FST). However, SAC $(120 \mathrm{mg} / \mathrm{kg})$ enhanced $\mathrm{Cu}, \mathrm{Zn}$-SOD activity in MB (34\%, Figure 7A) as compared to the imipramine-FST group and decreased it in PFC after FST compared to the vehicle-FST group (29\%, Figure 7B). This reduction in PFC suggests that SAC exerts a previous mechanism as a free radical scavenger which prevents the enhancement of $\mathrm{Cu}, \mathrm{Zn}-\mathrm{SOD}$ in this brain region. No changes were found in $\mathrm{HP}$ in the different treatment groups $(\mathrm{F}(3,28)=1.151$; $p=0.346$; Figure 7C).

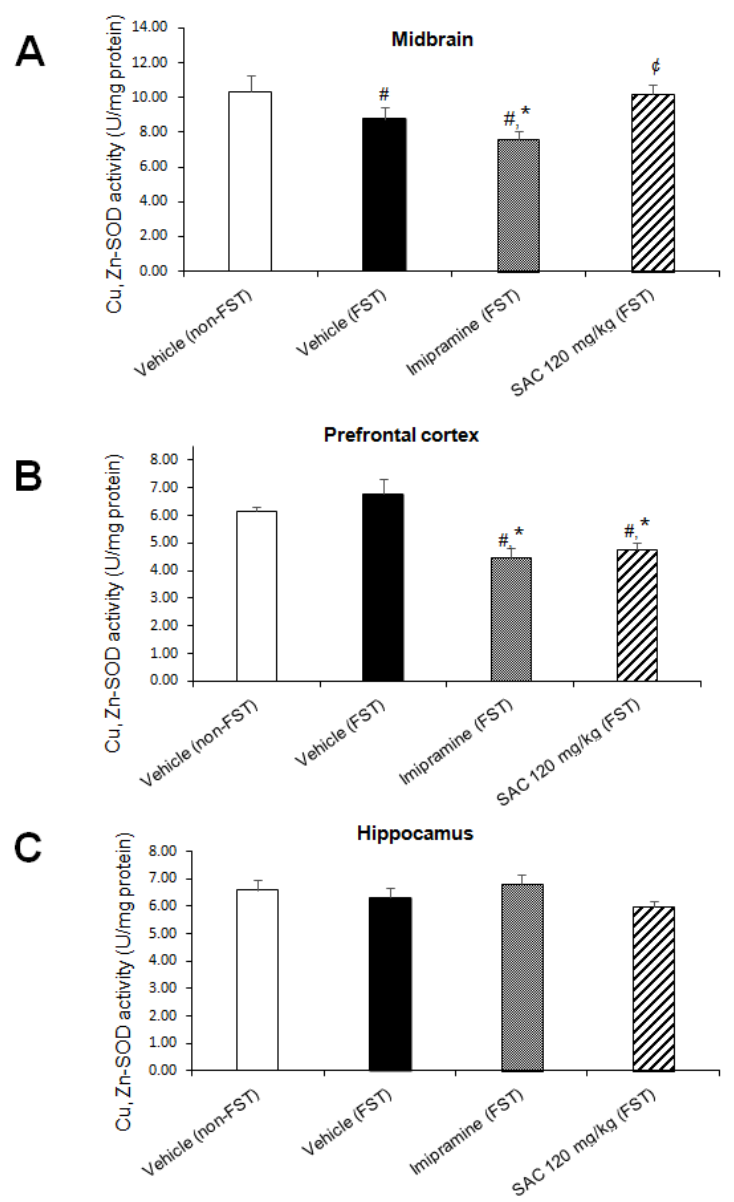

Figure 7. The antidepressant-like response of SAC $(120 \mathrm{mg} / \mathrm{kg})$ in the FST is related with downregulation of $\mathrm{Cu}, \mathrm{Zn}$-SOD activity in prefrontal cortex. The vehicle (non-FST or FST), imipramine (FST) or SAC (FST) were the treatment groups. Cu,Zn-SOD was analyzed in the midbrain (A), prefrontal cortex (B), and hippocampus (C). Results are expressed as mean \pm SEM of 6-8 animals per group. The one-way ANOVA followed by post hoc Duncan's tests was used to analyze the differences among groups. (\#) Statistically different from the non-FST group, $p<0.05$, Duncan's test; $\left(^{*}\right)$ statistically different from the vehicle-FST group, $p<0.05$, Duncan's test; ( $($ ) statistically different from the imipramine-FST group, $p<0.05$, Duncan's test. $\mathrm{Cu}, \mathrm{Zn}-\mathrm{SOD}=$ copper, zinc-superoxide dismutase; $\mathrm{FST}=$ forced swimming test; $\mathrm{SAC}=\mathrm{S}$-allyl cysteine. 
We found that GPx activity was significantly different among groups in PFC (F (3, $26=9.744$, $p=0.000$; Figure 8B). Post hoc multiple comparisons (Duncan post hoc $p<0.05$ ) showed a significant enhancement after FST as compared to the non-FST group (25\%). Imipramine reduced GPx activity after FST compared to the control group (vehicle-FST, 34\%). However, SAC (120 mg/kg) treatment enhanced GPx activity in mice exposed to FST versus the imipramine-FST group (59\%, Figure 8B). No differences were found in $\mathrm{MB}(\mathrm{F}(3,29)=0.247 ; p<0.862$; Figure $8 \mathrm{~A})$ and $\mathrm{HP}(\mathrm{F}(3,28)=1.603$; $p=0.211$; Figure 8C).

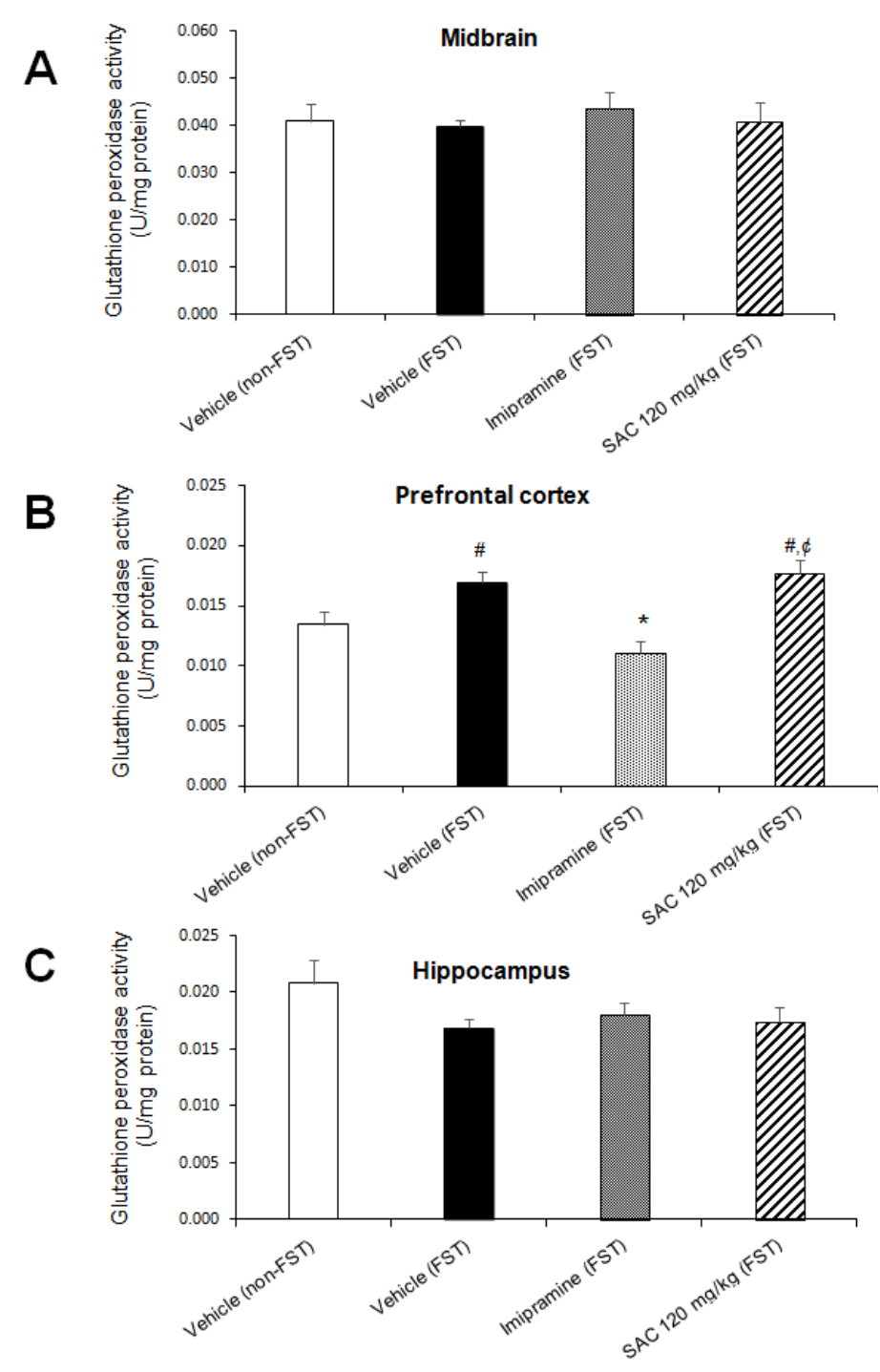

Figure 8. Effect of SAC on GPx activity in different brain regions in mice subjected to FST. The vehicle (non-FST or FST), imipramine (FST) or SAC $(120 \mathrm{mg} / \mathrm{kg})$ were the treatment groups. SAC did not change GPx activity in the midbrain (A), prefrontal cortex (B), or hippocampus (C) in FST vs. vehicle-FST group. Results are expressed as mean \pm SEM of 7-9 animals per group. The one-way ANOVA followed by post hoc Duncan's tests was used to analyze the differences among groups. (\#) statistically different from vehicle non-FST group, $p<0.05$, Duncan's test; $\left({ }^{*}\right)$ statistically different from vehicle-FST group, $p<0.05$, Duncan's test; $(₫)$ statistically different from imipramine (FST) group, $p<0.05$, Duncan's test. $\mathrm{FST}=$ forced swimming test; $\mathrm{SAC}=\mathrm{S}$-allyl cysteine; $\mathrm{GPx}=$ glutathione peroxidase .

No changes were found in GR activity (Figure 9) in $\operatorname{MB}(F(3,28)=2.688 ; p=0.066$, $\operatorname{PFC}(\mathrm{F}(3,25)=0.942 ; p=0.435)$ and $\operatorname{HP}(\mathrm{F}(3,29)=0.374 ; p=0.773)$. 


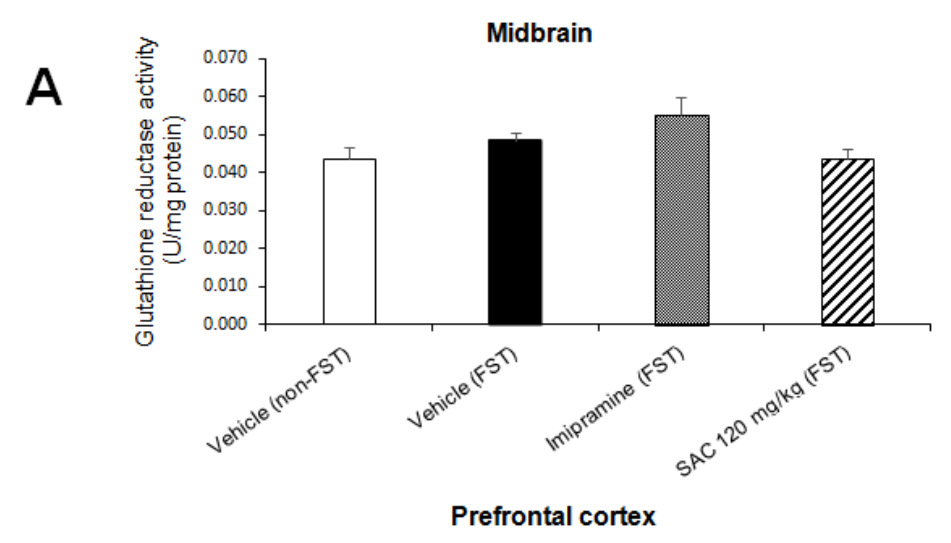

B
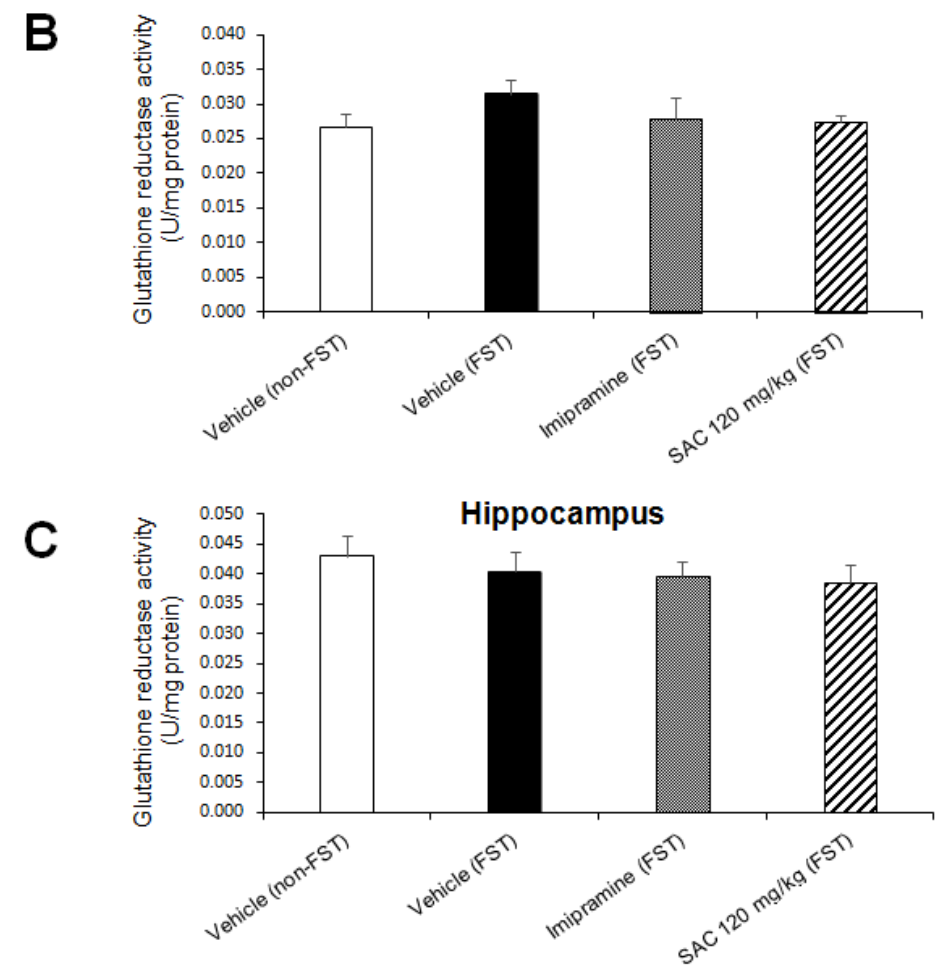

Figure 9. Effect of SAC on GR activity in different brain regions in mice exposed to FST. The vehicle (non-FST or FST), imipramine (FST) or SAC $(120 \mathrm{mg} / \mathrm{kg})$ were the treatment groups. SAC did not change GR activity in the midbrain (A), prefrontal cortex (B) or hippocampus (C) in FST vs. vehicle-FST group. Results are expressed as mean \pm SEM of 7-9 animals per group. Results were analyzed using one-way ANOVA. FST = forced swimming test; SAC = S-allyl cysteine; GR = glutathione reductase.

\section{Discussion}

Treatment for depression using antidepressant drugs results in remission, but with severe adverse effects and low response rates. The new therapies from natural resources have been used in psychiatric treatment due to greater patient compliance and mild side effects [27]. In particular, SAC, an active compound of aged garlic extract, is a potent antioxidant agent [14], with neuroprotective effects against oxidative damage in diverse animal models [14-16]. In this sense, it has been suggested that oxidative stress plays an essential role in depression $[5,28]$, as well as in animal models for depression-like behavior $[8,19,20]$. Therefore, antioxidant compounds could have an antidepressant effect, which is supported by preclinical studies [29]. The current study introduces the antidepressant-like effect of SAC, accompanied, mainly, by a reduction in hippocampal oxidative damage induced by the FST model. 
This research reports that the antidepressant-like effect of SAC was present at the four doses tested. The highest protection was observed at the $120 \mathrm{mg} / \mathrm{kg}$ dose, which produced a significant decrease $(44 \%)$ in immobility time in the FST, with a better profile than the classical antidepressant imipramine (29\%). We analyzed spontaneous locomotor activity to avoid false positives in the FST, to exclude the possibility that the reduction in immobility time produced by SAC may be associated with alterations in locomotor activity. Thus, we found that SAC treatment at $120 \mathrm{mg} / \mathrm{kg}$ did not affect this behavior, suggesting that this compound exerts a selective antidepressant-like response.

Additionally, FST is an animal test that can induce oxidative stress $[8,19]$. Therefore, we explored whether antidepressant-like effects of SAC are related to its anti-oxidative role in this model. For this purpose, we analyzed different oxidative stress markers (ROS levels, $\mathrm{O}_{2}{ }^{\bullet-}$ production, LPx, and antioxidant enzymes activities) in three different brain regions; the MB, PFC, and HP.

These brain regions are related to symptoms commonly presented in depressed patients [30] and form part of two circuits. The first is the mesocortical pathway, which originates from ventral tegmental area (VTA), localized in the MB, and projects to the PFC and anterior cingulate cortex. The mesolimbic pathway also projects from VTA to different brain regions including HP. Our results show that the SAC effect in the FST produced a reduction in some oxidative stress markers in the brain regions analyzed. No changes were found in $\mathrm{O}_{2}{ }^{\bullet-}$ production and LPx, nor GPx, GR, and Cu, Zn-SOD activities in MB after SAC administration in animals exposed to FST vs. the vehicle-FST group, although SAC treatment showed a trend to reduce $\mathrm{O}_{2}{ }^{--}$production. Nevertheless, Mn-SOD activity in MB was reduced significantly in the SAC group exposed to FST. It is suggested that an early mechanism induced by SAC during the first day is acting as an $\mathrm{O}_{2}{ }^{\bullet-}$ scavenger that prevents enhancement of Mn-SOD activity on the second day. Mn-SOD facilitates dismutation of $\mathrm{O}_{2}{ }^{\bullet-}$ that produces $\mathrm{H}_{2} \mathrm{O}_{2}$ in mitochondria, and it is removed by catalase and GPx enzymes preventing the formation of hydroxyl radicals [31]. However, the reduction in Mn-SOD activity by SAC did not change, indirectly suggesting no generation of $\mathrm{H}_{2} \mathrm{O}_{2}$, and therefore no changes in GPx activity.

Another important region is the PFC that participates in the temporal organization of behavior [32], and supports cognitive abilities that are required to organize behavior in time and context through connections with the limbic (including HP), cognitive, sensory, and motor regions following stimulation. In our study, the analysis of oxidative markers in PFC showed no changes in ROS levels, $\mathrm{O}_{2}{ }^{\bullet-}$ production, LPx, Mn-SOD, GPx, or GR activities after SAC administration in the FST model. However, SAC significantly decreased $\mathrm{Cu}, \mathrm{Zn}$-SOD activity in PFC in mice exposed to FST. This also suggests that SAC prevented oxidative stress, in part, due to $\mathrm{O}_{2}{ }^{\bullet-}$ scavenging effect, since $\mathrm{Cu}, \mathrm{Zn}-\mathrm{SOD}$ activity was reduced in PFC. This could be related to a previous mechanism as a free radical scavenger due to SAC on the first day of the FST which prevents enhancement of $\mathrm{Cu}, \mathrm{Zn}$-SOD on the second day of the test.

The HP plays an important role in the adjustment of learning, memory and emotion regulation [33] of contextual information of the environment. The oxidative stress assays in HP showed no differences in $\mathrm{O}_{2}{ }^{\bullet-}$ production, nor Cu,Zn-SOD, GPx, and GR activities after SAC administration in the FST model. However, SAC treatment showed a trend to reduce $\mathrm{O}_{2}{ }^{\bullet-}$ production. Nonetheless, SAC administration produced a significant reduction in LPx and Mn-SOD activity after FST compared to the control group (vehicle-FST). This suggests that SAC prevented LPx related to scavenging $\mathrm{O}_{2}{ }^{\bullet-}$ on the first day of FST, since mitochondrial antioxidant Mn-SOD activity was reduced on the second day of FST.

These results support the role of oxidative stress in depression [2]. The enhancement of MDA levels, an index of LPx, has been reported in major depression in samples of serum [34], as well as peripheral blood [34]. Moreover, treatment with antidepressants reduced MDA levels [35]. We found that FST elevated LPx in HP as previously reported [8], and SAC prevented this effect in a similar manner to imipramine. It is also well known that SAC prevents LPx [14], which supports our findings. In addition, a positive correlation was found between increased SOD serum levels and the severity of depressive symptoms [36]. We showed a reduction in Mn-SOD activity in the SAC-FST group 
compared to the FST group in MB and $\mathrm{HP}$, as well as a reduction in $\mathrm{Cu}, \mathrm{Zn}$-SOD activity in the SAC-FST group compared to the FST group in PFC.

In this context, it is well-known that SAC exerts an antioxidant action and scavenges $\mathrm{O}_{2}{ }^{\bullet-}$ [14]. Additionally, SAC has a neuroprotective effect against oxidative damage in the brain in diverse animal models of neurological/neurodegenerative diseases $[15,16,37]$. Therefore, it is suggested that an early mechanism induced by SAC during the first day of FST is to act as an $\mathrm{O}_{2}{ }^{\bullet-}$ scavenger, and preventing the enhancement of Mn-SOD activity in MB and $\mathrm{HP}$, which is indicated by a downregulation of Mn-SOD activity on the second day of the FST where we found an antidepressant-like effect. The same pattern was found but with a reduction in $\mathrm{Cu}, \mathrm{Zn}$-SOD activity in PFC. Our findings suggest that SAC produced activation of an endogenous antioxidative mechanism with the first line of defense related to mitochondrial antioxidant Mn-SOD activity in HP since two oxidative stress markers were reduced in this brain region.

SOD is a very important enzyme in reducing oxidative stress. It has been reported that Mn-SOD is abundant in neurons, and $\mathrm{Cu}, \mathrm{Zn}$-SOD is enriched in astrocytes with lower levels in neurons [38]. These antioxidant enzymes have different distribution in brain regions $[39,40]$. However, neurons are highly vulnerable to a reduction in $\mathrm{Mn}$-SOD as compared to $\mathrm{Cu}, \mathrm{Zn}$-SOD. In addition, SOD activity results in $\mathrm{H}_{2} \mathrm{O}_{2}$ production, but if catalase or GPx do not remove it, then the SOD overexpression can exacerbate brain damage. In addition, neurons are unable to enhance the expression of GPx, even with an increase in free radical production [41]. Therefore, neurons may have a limited capacity for ROS detoxification, which can interact with cellular lipids, proteins, and DNA, leading to cellular dysfunction and sometimes cell death.

The present study showed that SAC administration in mice exposed to FST resulted in brain region-specific changes, with the main changes being in the HP. This can be related to the modulation of the response in each region, attributed to compensatory mechanisms to counteract the possible detrimental effects associated with oxidative stress, as well as different properties of the stressor with multiple physiological effects, distinct cell composition for each brain region [42], and different metabolic rate to process information per brain region [43]. Additionally, the role of biological (strain, age, body, weight, gender, individual differences between animals), environmental, and physical factors (light, noise, food manipulations, handling, enriched environment, schedule, routes of treatment, time-course of analysis) should be considered.

In this regard, we reported differences on the second day of the FST, although several changes may occur during the first day of FST, which was not analyzed. It is important to note that different molecular mechanisms are activated during the first hours of exposure; for example, enhancement of hippocampal RNA expression of glucocorticoid-responsive genes [44], increase in hippocampal mineralocorticoid receptors [45], and epigenetic changes related to gene transcription [46]. Epigenetic processes may play an important role in stress-related mental disorders such as depression [47]. Further studies need to be performed during the first day of FST to explore the early molecular mechanisms leading to the SAC antidepressant-like effect on the second day in the different brain regions. It is also important to note that SAC is widely used, has notable clinical safety evidence, and crosses the blood-brain barrier [14], and is therefore a candidate for further investigation, especially for the treatment of depression.

\section{Conclusions}

We showed that SAC has antidepressant-like properties, which could be associated, in part, with its antioxidant role mainly in the HP, and a modulated response in other brain regions. Our results indicate that the antidepressant-like effect of SAC was slightly higher (44\%) than the effect observed with a classical antidepressant drug, imipramine (29\%), in the FST. However, our findings need to be repeated in other animal tests and models of depression.

Author Contributions: P.R. conceived, designed, performed experiments, interpreted results of the experiments, and wrote the manuscript. E.R.-S. performed experiments, analyzed the data, interpreted results, edited, and revised the manuscript. P.D.M. synthesized SAC, edited, and revised the manuscript. O.N.M.-C., and J.P.-C. performed 
experiments, edited and revised manuscript. All authors have read and agreed to the published version of the manuscript.

Funding: This research was partially funded by the National Council of Science and Technology of Mexico (CONACyT) CB-2008-01 No. 106619.

Acknowledgments: We thank Robyn Elizabeth Hudson for her valuable comments and Miguel Hernández Hernández for his technical assistance.

Conflicts of Interest: The authors declare no conflict of interest. The funders had no role in the design of the study; in the collection, analyses, or interpretation of data; in the writing of the manuscript, or in the decision to publish the results.

\section{References}

1. Kessler, R.C.; Bromet, E.J. The Epidemiology of Depression across Cultures. Annu. Rev. Public Health 2013, 34, 119-138. [CrossRef] [PubMed]

2. Vavakova, M.; Ďuračková, Z.; Trebatická, J. Markers of Oxidative Stress and Neuroprogression in Depression Disorder. Oxid. Med. Cell. Longev. 2015, 2015, 1-12. [CrossRef] [PubMed]

3. Lindqvist, D.; Dhabhar, F.S.; James, S.J.; Hough, C.M.; Jain, F.A.; Bersani, F.S.; Reus, V.I.; Verhoeven, J.E.; Epel, E.S.; Mahan, L.; et al. Oxidative stress, inflammation and treatment response in major depression. Psychoneuroendocrinology 2017, 76, 197-205. [CrossRef] [PubMed]

4. Maes, M.; Mihaylova, I.; Kubera, M.; Uytterhoeven, M.; Vrydags, N.; Bosmans, E. Increased plasma peroxides and serum oxidized low density lipoprotein antibodies in major depression: Markers that further explain the higher incidence of neurodegeneration and coronary artery disease. J. Affect. Disord. 2010, 125, 287-294. [CrossRef] [PubMed]

5. Wigner, P.; Czarny, P.; Galecki, P.; Su, K.-P.; Sliwinski, T. The molecular aspects of oxidative \& nitrosative stress and the tryptophan catabolites pathway (TRYCATs) as potential causes of depression. Psychiatry Res. 2018, 262, 566-574. [CrossRef] [PubMed]

6. Halliwell, B. Free radicals and antioxidants: Updating a personal view. Nutr. Rev. 2012, 70, $257-265$. [CrossRef]

7. Xu, Y.; Wang, C.; Klabnik, J.J.; O’Donnell, J.M. Novel Therapeutic Targets in Depression and Anxiety: Antioxidants as a Candidate Treatment. Curr. Neuropharmacol. 2014, 12, 108-119. [CrossRef]

8. Rojas, P.; Serrano-García, N.; Medina-Campos, O.N.; Pedraza-Chaverri, J.; Ögren, S.O.; Rojas, C. Antidepressant-like effect of a Ginkgo biloba extract (EGb761) in the mouse forced swimming test: Role of oxidative stress. Neurochem. Int. 2011, 59, 628-636. [CrossRef]

9. Kaufmann, F.N.; Gazal, M.; Bastos, C.R.; Kaster, M.P.; Ghisleni, G. Curcumin in depressive disorders: An overview of potential mechanisms, preclinical and clinical findings. Eur. J. Pharmacol. 2016, 784, $192-198$. [CrossRef]

10. Moore, A.; Beidler, J.; Hong, M.Y. Resveratrol and Depression in Animal Models: A Systematic Review of the Biological Mechanisms. Molecules 2018, 23, 2197. [CrossRef]

11. Chauhan, N.B. Effect of aged garlic extract on APP processing and tau phosphorylation in Alzheimer's transgenic model Tg2576. J. Ethnopharmacol. 2006, 108, 385-394. [CrossRef]

12. Agbana, Y.L.; Ni, Y.; Zhou, M.; Zhang, Q.; Kassegne, K.; Karou, S.D.; Kuang, Y.; Zhu, Y. Garlic-derived bioactive compound S-allylcysteine inhibits cancer progression through diverse molecular mechanisms. Nutr. Res. 2020, 73, 1-14. [CrossRef] [PubMed]

13. Asdaq, S.M.B. Antioxidant and Hypolipidemic Potential of Aged Garlic Extract and Its Constituent, S-Allyl Cysteine, in Rats. Evid. Based Complement. Altern. Med. 2015, 2015, 1-7. [CrossRef] [PubMed]

14. Colín-González, A.L.; Santana, R.A.; Silva-Islas, C.A.; Chánez-Cárdenas, M.E.; Santamaría, A.; Maldonado, P.D. The Antioxidant Mechanisms Underlying the Aged Garlic Extract- and S-Allylcysteine-Induced Protection. Oxid. Med. Cell. Longev. 2012, 2012, 1-16. [CrossRef] [PubMed]

15. Rojas, P.; Serrano-García, N.; Medina-Campos, O.N.; Pedraza-Chaverri, J.; Maldonado, P.D.; Ruiz-Sánchez, E. S-Allylcysteine, a garlic compound, protects against oxidative stress in 1-methyl-4-phenylpyridinium-induced parkinsonism in mice. J. Nutr. Biochem. 2011, 22, 937-944. [CrossRef] [PubMed] 
16. Ray, B.; Chauhan, N.B.; Lahiri, D.K. The "Aged Garlic Extract"(AGE) and One of its Active Ingredients S-Allyl-L-Cysteine (SAC) as Potential Preventive and Therapeutic Agents for Alzheimer's Disease (AD). Curr. Med. Chem. 2011, 18, 3306-3313. [CrossRef]

17. Porsolt, R.D.; Le Pichon, M.; Jalfre, M. Depression: A new animal model sensitive to antidepressant treatments. Nature 1977, 266, 730-732. [CrossRef]

18. Petit-Demouliere, B.; Chenu, F.; Bourin, M. Forced swimming test in mice: A review of antidepressant activity. Psychopharmacology 2004, 177, 245-255. [CrossRef]

19. Akhtar, M.; Pillai, K.K.; Vohora, D. Effect of Thioperamide on Modified Forced Swimming Test-Induced Oxidative Stress in Mice. Basic Clin. Pharmacol. Toxicol. 2005, 97, 218-221. [CrossRef]

20. Gorlova, A.; Pavlov, D.; Zubkov, E.; Zorkina, Y.A.; Inozemtsev, A.; Morozova, A.; Chekhonin, V. Alteration of oxidative stress markers and behavior of rats in a novel model of depression. Acta Neurobiol. Exp. 2019, 79, 232-238. [CrossRef]

21. Maldonado, P.D.; Alvarez-Idaboy, J.R.; Aguilar-González, A.; Lira-Rocha, A.; Jung-Cook, H.; Medina-Campos, O.N.; Pedraza-Chaverri, J.; Galano, A. Role of Allyl Group in the Hydroxyl and Peroxyl Radical Scavenging Activity of S-Allylcysteine. J. Phys. Chem. B 2011, 115, 13408-13417. [CrossRef] [PubMed]

22. Rojas, P.; Joodmardi, E.; Hong, Y.; Perlmann, T.; Ögren, S.O. Adult mice with reduced Nurr1 expression: An animal model for schizophrenia. Mol. Psychiatry 2007, 12, 756-766. [CrossRef] [PubMed]

23. Filip, M.; Cunningham, K.A. Hyperlocomotive and Discriminative Stimulus Effects of Cocaine Are Under the Control of Serotonin2C (5-HT2C) Receptors in Rat Prefrontal Cortex. J. Pharmacol. Exp. Ther. 2003, 306, 734-743. [CrossRef] [PubMed]

24. Satoh, M.; Fujimoto, S.; Haruna, Y.; Arakawa, S.; Horike, H.; Komai, N.; Sasaki, T.; Tsujioka, K.; Makino, H.; Kashihara, N. NAD(P)H oxidase and uncoupled nitric oxide synthase are major sources of glomerular superoxide in rats with experimental diabetic nephropathy. Am. J. Physiol. Ren. Physiol. 2005, 288, F1144-F1152. [CrossRef] [PubMed]

25. Crow, J.P. Dichlorodihydrofluorescein and Dihydrorhodamine 123 Are Sensitive Indicators of Peroxynitritein Vitro:Implications for Intracellular Measurement of Reactive Nitrogen and Oxygen Species. Nitric Oxide 1997, 1, 145-157. [CrossRef] [PubMed]

26. Rojas, P.; Serrano-García, N.; Mares-Sámano, J.J.; Medina-Campos, O.N.; Pedraza-Chaverri, J.; Ögren, S.O. EGb761 protects against nigrostriatal dopaminergic neurotoxicity in 1-methyl-4-phenyl-1,2,3,6-tetrahydropyridine-induced Parkinsonism in mice: Role of oxidative stress. Eur. J. Neurosci. 2008, 28, 41-50. [CrossRef]

27. Thachil, A.; Mohan, R.; Bhugra, D. The evidence base of complementary and alternative therapies in depression. J. Affect. Disord. 2007, 97, 23-35. [CrossRef]

28. Maes, M.; Galecki, P.; Chang, Y.S.; Berk, M. A review on the oxidative and nitrosative stress (O\&NS) pathways in major depression and their possible contribution to the (neuro)degenerative processes in that illness. Prog. Neuro-Psychopharmacol. Biol. Psychiatry 2011, 35, 676-692. [CrossRef]

29. Behr, G.A.; Moreira, J.C.F.; Frey, B.N. Preclinical and Clinical Evidence of Antioxidant Effects of Antidepressant Agents: Implications for the Pathophysiology of Major Depressive Disorder. Oxid. Med. Cell. Longev. 2012, 2012, 1-13. [CrossRef]

30. Liu, W.; Ge, T.; Leng, Y.; Pan, Z.; Fan, J.; Yang, W.; Cui, R. The Role of Neural Plasticity in Depression: From Hippocampus to Prefrontal Cortex. Neural Plast. 2017, 2017, 1-11. [CrossRef]

31. Saso, L.; Firuzi, O. Pharmacological applications of antioxidants: Lights and shadows. Curr. Drug Targets 2014, 15, 1177-1199. [CrossRef] [PubMed]

32. McEwen, B.S.; Morrison, J.H. The brain on stress: Vulnerability and plasticity of the prefrontal cortex over the life course. Neuron 2013, 79, 16-29. [CrossRef] [PubMed]

33. Anacker, C.; Hen, R. Adult hippocampal neurogenesis and cognitive flexibility—Linking memory and mood. Nat. Rev. Neurosci. 2017, 18, 335-346. [CrossRef]

34. Khanzode, S.D.; Dakhale, G.N.; Khanzode, S.S.; Saoji, A.; Palasodkar, R. Oxidative damage and major depression: The potential antioxidant action of selective serotonin re-uptake inhibitors. Redox Rep. 2003, 8, 365-370. [CrossRef] [PubMed]

35. Gałecki, P.; Szemraj, J.; Bieńkiewicz, M.; Zboralski, K.; Gałecka, E. Oxidative stress parameters after combined fluoxetine and acetylsalicylic acid therapy in depressive patients. Hum. Psychopharmacol. Clin. Exp. 2009, 24, 277-286. [CrossRef] 
36. Sarandol, A.; Sarandol, E.; Eker, S.S.; Erdinc, S.; Vatansever, E.; Kirli, S. Major depressive disorder is accompanied with oxidative stress: Short-term antidepressant treatment does not alter oxidative-Antioxidative systems. Hum. Psychopharmacol. Clin. Exp. 2007, 22, 67-73. [CrossRef]

37. Numagami, Y.; Ohnishi, S.T. S-allylcysteine inhibits free radical production, lipid peroxidation and neuronal damage in rat brain ischemia. J. Nutr. 2001, 131, 1100S-1105S. [CrossRef]

38. Lindenau, J.; Noack, H.; Possel, H.; Asayama, K.; Wolf, G. Cellular distribution of superoxide dismutases in the rat CNS. Glia 2000, 29, 25-34. [CrossRef]

39. Zhang, P.; Anglade, P.; Hirsch, E.C.; Javoy-Agid, F.; Agid, Y. Distribution of manganese-dependent superoxide dismutase in the human brain. Neuroscience 1994, 61, 317-330. [CrossRef]

40. Bergeron, C.; Petrunka, C.; Weyer, L. Copper/zinc superoxide dismutase expression in the human central nervous system. Correlation with selective neuronal vulnerability. Am. J. Pathol. 1996, 148, 273-279.

41. Lindenau, J.; Noack, H.; Asayama, K.; Wolf, G. Enhanced cellular glutathione peroxidase immunoreactivity in activated astrocytes and in microglia during excitotoxin induced neurodegeneration. Glia 1998, 24, 252-256. [CrossRef]

42. Herculano-Houzel, S.; Mota, B.; Lent, R. Cellular scaling rules for rodent brains. Proc. Natl. Acad. Sci. USA 2006, 103, 12138-12143. [CrossRef] [PubMed]

43. Kleinridders, A.; Ferris, H.A.; Reyzer, M.L.; Rath, M.; Soto, M.; Manier, M.L.; Spraggins, J.; Yang, Z.; Stanton, R.C.; Caprioli, R.M.; et al. Regional differences in brain glucose metabolism determined by imaging mass spectrometry. Mol. Metab. 2018, 12, 113-121. [CrossRef] [PubMed]

44. Mifsud, K.R.; Reul, J.M. Acute stress enhances heterodimerization and binding of corticosteroid receptors at glucocorticoid target genes in the hippocampus. Proc. Natl. Acad. Sci. USA 2016, 113, 11336-11341. [CrossRef] [PubMed]

45. Gesing, A.; Bilang-Bleuel, A.; Droste, S.K.; Linthorst, A.; Holsboer, F.; Reul, J.M. Psychological Stress Increases Hippocampal Mineralocorticoid Receptor Levels: Involvement of Corticotropin-Releasing Hormone. J. Neurosci. 2001, 21, 4822-4829. [CrossRef]

46. Collins, A.; Hill, L.E.; Chandramohan, Y.; Whitcomb, D.J.; Droste, S.K.; Reul, J.M. Exercise Improves Cognitive Responses to Psychological Stress through Enhancement of Epigenetic Mechanisms and Gene Expression in the Dentate Gyrus. PLoS ONE 2009, 4, e4330. [CrossRef]

47. Reul, J.M. Making Memories of Stressful Events: A Journey Along Epigenetic, Gene Transcription, and Signaling Pathways. Front. Psychol. 2014, 5, 1-11. [CrossRef] 